\title{
Ectopic ACTH syndrome from bronchogenic carcinoma in association with chronic lymphocytic leukaemia
}

\author{
J. C. FORFAR \\ B.Sc., M.R.C.P. \\ The Royal Infirmary, Edinburgh
}

\begin{abstract}
Summary
A patient under treatment for chronic lymphocytic leukaemia developed lobar pneumonia after 8 months. When antileukaemic therapy was discontinued, features of an ectopic ACTH syndrome developed, secondary to bronchogenic carcinoma. Exogenous steroid therapy for leukaemia seemed to suppress the clinical manifestations of the ectopic ACTH syndrome while subsequent endogenous steroid production controlled the peripheral lymphocyte count.
\end{abstract}

\section{Introduction}

The coexistence in one patient of 2 unrelated neoplastic diseases is unusual and becomes exceptional when one of the tumours manifests itself by ectopic hormone production.

\section{Case report}

A 62-year-old man who had smoked 30 cigarettes/ day for 40 years presented with night sweats, $3.5 \mathrm{~kg}$ weight loss and left hypochondrial pain. The liver was enlarged $4 \mathrm{~cm}$ and there was a friction rub over the spleen which was palpable $6 \mathrm{~cm}$ below the costal margin. There was no lymphadenopathy. The WBC was $38 \times 10^{9} / 1$ with $93 \%$ small, mature lymphocytes; $\mathrm{Hb}$, platelet count, Coombs' test and immunoglobulin estimations were normal, but sternal marrow showed diffuse infiltration with small, uniform, mature lymphocytes; plasma urate was $0.42 \mathrm{mmol} / \mathrm{l}$, and chest X-ray was normal. He was diagnosed as suffering from chronic lymphocytic leukaemia and was initially treated with chlorambucil $8 \mathrm{mg} /$ day and prednisolone $30 \mathrm{mg} /$ day.

He remained relatively well for 8 months until admitted to hospital as an emergency with a 3-week history of cough and purulent sputum over the previous week and a 6-hr history of left sided chest pain of pleuritic type. He was taking chlorambucil $8 \mathrm{mg}$ daily and prednisolone $10 \mathrm{mg}$ daily. A clinical diagnosis of lobar pneumonia was confirmed radiologically. Gross hepatosplenomegaly was present without associated lymphadenopathy. His WBC count was $10.6 \times 10^{9} / 1$ with $43 \%$ neutrophils, $52 \%$ lymphocytes and 5\% monocytes; $\mathrm{Hb} 12.2 \mathrm{~g} / \mathrm{dl}$; platelets $103 \times 10^{9} / 1$ and normal liver function tests, apart from a reduced plasma albumin at $31 \mathrm{~g} / \mathrm{l}$. Plasma calcium levels were normal. Although a full infection screen revealed no significant pathogens, the patient was treated with parenteral ampicillin and cloxacillin. Chlorambucil therapy was stopped and prednisolone tailed-off after an initial increase in dosage to cover the acute stage of the pneumonia. An early response to this therapy was not maintained and intermittent pyrexia and malaise returned. Chest X-ray showed the development of bilateral hilar enlargement with little evidence of clearance of the pneumonic process.

During the second week of illness, the chronic lymphocytic leukaemia appeared well controlled with total WBC count between 10 and $15 \times 10^{9} / 1$ with 40-50\% lymphocytes, but a persistent hypokalaemic alkalosis developed. During the third week further deterioration occurred with the development of pulmonary and marked peripheral oedema which responded poorly to diuretic therapy. There was no clinical, radiographic or electrocardiographic evidence of cardiac disease. The clinical picture was of salt and water overload. Plasma cortisol levels were estimated fluorimetrically and found to be markedly elevated at $1050 \mathrm{mmol} / \mathrm{l} 2$ weeks after admission rising to a peak of $4025 \mathrm{mmol} / \mathrm{l}$ after 4 weeks. Plasma corticotrophin (ACTH) and lipotrophin (LPH) levels, measured by radioimmunoassay, were grossly elevated at $1671 \mathrm{ng} / \mathrm{l}$ and $35550 \mathrm{ng} / \mathrm{l}$ respectively. Rigid bronchoscopy showed no evidence of tumour in the main or segmental bronchi but profuse mucoid secretion throughout the bronchial tree.

The patient deteriorated rapidly during the fourth week of illness. Fluid retention with associated oliguria proved resistant to large doses of frusemide and bumetanide. The patient was treated with metyrapone $500 \mathrm{mg}$ orally 4-hourly and aminoglutethimide $250 \mathrm{mg}$ orally 8 -hourly to block steroid production and hence facilitate diuresis, but although concentrations of cortisol in the plasma fell to 357 $\mathrm{nmol} / \mathrm{l}$ within $24 \mathrm{hr}$ no clinical improvement was achieved and he died at the end of the fourth week.

At post-mortem tumour deposits were present in both hilar lymph nodes, but no tumour was identified within the bronchial lumina. The primary site 
was central but could not be localized with precision. Histology showed a poorly differentiated oat cell carcinoma of lung. Gross pulmonary oedema was confirmed. An enlarged liver contained numerous metastatic deposits with the same histological features as the hilar nodes. Sections of spleen (weight $1300 \mathrm{~g}$ ) and para-aortic nodes showed features compatible with chronic lymphocytic leukaemia and marrow examination revealed focal aggregates of small lymphocytes consistent with this diagnosis. Both adrenal glands were enlarged with nodular hyperplasia on the left side and diffuse hyperplasia on the right. Examination of heart and pituitary revealed no macroscopic or microscopic abnormality. The ACTH and LPH content of the primary lung tumour was 375 and $4249 \mathrm{ng} / \mathrm{g}$ wet weight respectively, and of the liver secondaries 137 and $385 \mathrm{ng} / \mathrm{g}$ wet weight. The amounts of ACTH and LPH in the spleen and para-aortic nodes were insignificant confirming the lung tumour as the source of the ectopic hormone production.

\section{Discussion}

Ectopic hormone-producing syndromes become apparent clinically in about $10 \%$ of cases of lung carcinoma and of these, between $5 \%$ and $20 \%$ are manifested by adreno-cortical overactivity (Azzopardi, Freeman and Poole, 1970). The association between non-endocrine tumours and adrenal hyperplasia (Brown, 1928) was first reported 4 years before Cushing's syndrome was described. Approximately 100 cases of this association have now been described in the literature (Ross, 1966; Rees and Ratcliffe, 1974). Very few were associated with other concurrent neoplasms. The present case is unique in its coupling and the therapeutic effect which the ACTH secreted by the bronchial carcinoma might have had on the chronic lymphocytic leukaemia. Second malignancies are said to occur with increased frequency in chronic lymphocytic leukaemia with a reported incidence of solid tumours ranging from $2 \cdot 5-34 \%$ (Sweet, Golomb and Ultmann, 1977). These second tumours tend to involve skin and colon and may be related to impaired immune surveillance. Bronchial carcinoma has not previously been reported in association with chronic lymphocytic leukaemia.
Plasma and tumour LPH levels were significantly higher than ACTH levels in keeping with the findings of Gilkes, Rees and Besser (1977) in ectopic hormone- $-\frac{\pi}{\mathbb{Q}}$ producing syndromes as opposed to pituitary over $\Omega$ secretion where the situation is reversed. Unfortunately, the mean survival for malignant hormone $\overrightarrow{\bar{*}}$ producing tumours is less than 3 months from diagnosis (Rees and Ratcliffe, 1974), and in the patient now reported it was less than one month.

Ectopic hormone production is considered to ber autonomous and unsusceptible to feedback inhibition. In this case, however, the clinical manifestations $s^{\infty}$ of ectopic ACTH production were apparent only $\overrightarrow{0}$ after steroid therapy for chronic lymphocyticleukaemia had been withdrawn. It is, therefore, $\omega$ conceivable that ACTH production in this tumouro was partially inhibited by the exogenous steroid 3 given for the chronic lymphocytic leukaemia, itsis. withdrawal allowing an increase in ACTH levels with the striking 4-fold rise in cortisol levels over the sub-? sequent 2 weeks. The very high concentrations of endogenous cortisol may also explain why the total peripheral lymphocyte count remained relativelyo low after the exogenous steroids had been wit\$drawn.

\section{Acknowledgments}

I am grateful to Dr R. M. Marquis, Dr S. H. Davies ăd Dr A. D. Toft for help in the preparation of this report a $8 \mathrm{~d}^{-}$ to Dr J. G. Ratcliffe for the assays of ACTH and LPH.

\section{References}

Azzopardi, J.G., Freeman, E. \& Poole, G. (1970) Endocrine and metabolic disorders in bronchial carcinoma. British Medical Journal, 4, 528.

Brown, W.H. (1928) A case of pluriglandular syndrome.응 Lancet, ii, 1022.

Gilkes, J.J.H., Rees, L.H. \& Besser, G.M. (1977) Plasma immunoreactive corticotrophin and lipotrophin in Cush-음 ing's syndrome and Addison's disease. British Medical Journal, 1, 996.

ReES, L.H. \& RATCliffe, J.G. (1974) Ectopic hormone pro-Oำ duction by non-endocrine tumours. Clinical Endocrinology 3, 263.

Ross, E.J. (1966) Endocrine syndromes of non-endocrine.origin. Proceedings of the Royal Society of Medicine, 59, 을 335 .

Sweet, D.L., Golomb, H.M. \& Ultmann, J.E. (1977) The clinical features of chronic lymphocytic leukaemia. In: Clinics in Haematology, 6, p. 185. Saunders, London. 